\title{
GEOPROCESSAMENTO APLICADO AO ESTUDO DE VULNERABILIDADE DO SOLO DA BACIA HIDROGRÁFICA DO CÓRREGO GUARIBAS EM UBERLÂNDIA-MG
}

\author{
GIS applied to the study of soil vulnerability of Guaribas Stream Water \\ Basin in Uberlândia-MG
}

\author{
Erich Vectore Pavanin ${ }^{1}$, Maria Lígia Chuerubim², Bruno de Oliveira Lázaro ${ }^{3}$
}

Recebido em 21 de julho de 2016; recebido para revisão em 07 de novembro de 2016; aceito em 20 de fevereiro de 2017; disponivel on-line em 05 de abril de 2017.

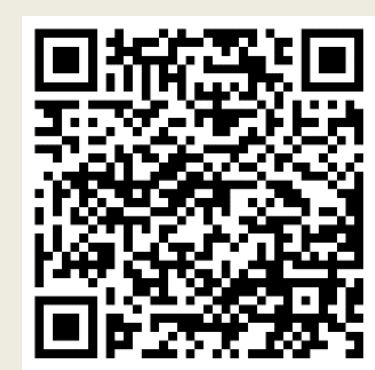

PALAVRAS CHAVE:

Engenharia urbana;

Geotecnia;

Geoprocessamento;

Vulnerabilidade do solo;

Bacia hidrográfica.

\section{KEYWORDS:}

Urban engineering

Geotechnics;

GIS;

Sail vulnerability;

Water basin.;

RESUMO: Este trabalho apresenta um estudo acerca da aplicação de técnicas de geoprocessamento na definição e caracterização dos graus de vulnerabilidade geotécnica do solo na Bacia Hidrográfica do Córrego Guariba em Uberlândia - MG. Observou-se, na área de estudo, ser necessário o estabelecimento de ferramentas de planejamento e gestão territorial que possibilitassem analisar e verificar o impacto da ocupação antrópica nas margens de córregos urbanos frente à ocorrência de processos erosivos. Desta maneira, o uso de geotecnologias, como o Sensoriamento Remoto, inseriu-se neste tipo de trabalho como sendo um mecanismo indispensável ao planejamento urbano, dado possibilitar, mediante a utilização de imagens de satélite e ferramentas de processamento digital, o mapeamento e caracterização geotécnica das bacias hidrográficas localizadas no Brasil. Nesta perspectiva, foram utilizadas neste trabalho imagens de softwares livres do ano de 2013 , bem como as ferramentas de processamento digital de imagens SPRINGS e AUTOCAD, com o intuito de identificar as classes de uso e ocupação do solo da área de estudo, a declividade da região, os tipos de materiais inconsolidados (solo) e a profundidade do nível d'água local. A partir do estabelecimento destes quatro planos de informação, utilizou-se o método de Análise de Multicritérios, denominado também AHP (Analystic Hierarchy Process), para correlacionar os dados obtidos e elaborar o mapa de vulnerabilidade do solo. Assim, este trabalho contribui para promover o diagnóstico da vulnerabilidade do solo à erosão na Bacia Hidrográfica do Córrego Guaribas em Uberlândia-MG e para a utilização deste dado como ferramenta de suporte no planejamento urbano sustentável.

ABSTRACT: This paper presents a study on the application of GIS techniques to define and characterize the degree of geotechnical soil vulnerability in Guaribas Stream Water Basin in Uberlândia - MG. It was observed in the study area, be necessary to establish planning and land use management tools that make possible to analyze and verify the impact of human occupation on the banks of urban streams across the occurrence of erosion. Thus, the use of geo-technologies, such as remote sensing, inserted in this type of work as an indispensable mechanism to urban planning, as possible, through the use of satellite images and digital processing tools, mapping and geotechnical characterization river basins located in Brazil. In this perspective, we were used in this study of 2013 years of free software images, as well as the digital processing tools SPRINGS and AUTOCAD images, in order to identify the classes of use and land cover in the study area, the slope of the region, the types of unconsolidated material (ground) level and the depth d local water. From the establishment of these four planes of information, we used the Multicriteria Analysis method, also called AHP (Analystic Hierarchy Process) to correlate the data and prepare the vulnerability map of erosion in the catchment area of Guaribas Stream. In that way, this work helps to promote the diagnosis of soil vulnerability to erosion in the Basin Guaribas stream in Uberlândia-MG and to use this data as a support tool for sustainable urban planning.

\footnotetext{
* Contato com os autores:

${ }^{1}$ e-mail: erich.vp@gmail.com ( E. V. Pavanin )

Mestre em geografia. Instituto de Geografia (IGUFU). Universidade Federal de Uberlândia (UFU).

2e-mail: marialigia@ufu.br (M. L. Chuerubim )

Doutoranda em Transportes e Mestre em Ciências Cartográficas, Docente, Fac. de Engenharia Civil (FECIV) - Universidade Federal de Uberlândia (UFU).

3e-mail: brunodeoliveira38@hotmail.com (B. O. Lázaro)

Discente de graduação em Engenharia Civil. Faculdade de Engenharia Civil (FECIV). Universidade Federal de Uberlândia (UFU).

${ }^{4}$ e-mail: nishi@ufu.br ( L. Nishiyama )

Doutorado em Geotécnica. Professor Associado II. Instituto de Geografia (IGUFU). Universidade Federal de Uberlândia (UFU).
} 


\section{INTRODUÇÃO}

As geotecnologias são definidas como sendo o conjunto de tecnologias para coleta, processamento, análise e oferta de informações com referências geográficas e espaciais bem definidas. Estes recursos tecnológicos são compostos por soluções em hardware e software que, juntas, funcionam como poderosas ferramentas para o auxílio no processo de tomada de decisões. Assim, entre as variadas geotecnologias, podem-se destacar os Sistemas de Informação Geográfica (SIGs), a cartografia digital, o Sensoriamento Remoto e os sistemas de posicionamento global GNSS (Global Navigation Satellite System) como sendo os seus principais expoentes contemporâneos (Rosa, 2005).

Neste contexto, as geotecnologias vêm sendo utilizadas ao redor do mundo para se elaborar estudos e diagnósticos relacionados à questão da vulnerabilidade ambiental dos espaços urbanos construídos e ocupados pelo homem. Embora já fosse abordada em estudos da década de 1970, esta temática começou a ganhar maior realce apenas no final dos anos de 1980 e inicio de 1990, quando as pesquisas deixaram de se ocupar apenas com os perigos naturais, passando a enfocar também os perigos sociais e os tecnológicos atrelados às questões ambientais e implicações geoespaciais da ocupação antrópica na biosfera.

Desta forma, o presente estudo corroborou a definição de Costa (2007) para vulnerabilidade ambiental, considerando-a como o grau de suscetibilidade, risco ou fragilidade que um determinado ambiente (seja ele natural ou antrópico) possui a um determinado tipo de impacto. No caso deste trabalho, restringiu-se como questão de estudo a vulnerabilidade à processos erosivos do solo da Bacia Hidrográfica do Córrego Guaribas, uma das principais redes naturais urbanas de drenagem do município de Uberlândia - MG.

A Bacia Hidrográfica do Córrego Guaribas se comporta como uma importante área de drenagem dentro dos limites urbanos do município de Uberlândia-MG. A região enfrenta, atualmente, uma série de problemas ambientais, econômicos, construtivos e sociais relacionados à dinâmica indevida de uso e ocupação de seu solo para diversas atividades antrópicas e à ocorrência de fenômenos erosivos. Neste sentido, tornou-se necessário promover um estudo de diagnóstico dos graus de vulnerabilidade do solo da bacia à erosão, de modo a proporcionar à administração pública escopo suficiente para auxiliar no processo de gestão territorial da bacia.

Dentro deste cenário, este trabalho lança mão de geotecnologias (tais como o Sensoriamento Remoto e o Geoprocessamento) para promover um diagnóstico da vulnerabilidade do solo da Bacia Hidrográfica do Córrego Guaribas. Com isso, oferece-se aos órgãos competentes dados e informações de grande importância para a prática eficiente do planejamento, execução e gestão territorial do município de Uberlândia - MG, de modo a auxiliar na redução dos diversos impactos ambientais e sociais existentes na área de drenagem do Guaribas, bem como promover a busca pelo desenvolvimento urbano sustentável tanto da bacia estudada quanto de todo o município.

\section{OBJETIVO}

Este trabalho objetivou elaborar um mapa da vulnerabilidade do solo à ocorrência de processos erosivos na Bacia Hidrográfica do Córrego Guaribas, localizada nos limites da zona urbana do município de Uberlândia - MG. Tal mapeamento teve a finalidade de promover dados e informações geoespaciais à administração pública e à população, referentes ao potencial de ocorrência de feições erosivas na área de drenagem do Córrego Guaribas. Com isso, objetivou-se também auxiliar o processo de gestão e parcelamento territorial da área, confluindo a dinâmica de uso e ocupação do solo local às restrições geotécnicas e demandas populacionais existentes na área de estudo. 


\section{REVISÃO BIBLIOGRÁFICA}

Vulnerabilidade ambiental é definida como sendo o grau, numericamente quantificado, de susceptibilidade, fragilidade ou risco que determinado espaço geográfico possui frente à ocorrência de algum impacto em seu ecossistema. Neste sentido, estudos que visam analisar a vulnerabilidade ambiental de determinadas unidades geográficas urbanas se configuram como importantes mecanismos para a compreensão das relações e dinâmicas existentes entre as comunidades que povoam a biosfera como um todo (Costa, 2007).

Neste sentido, os problemas ambientais urbanos dizem respeito tanto aos processos de construção da cidade, quanto às condições de vida da população que vive em áreas urbanas. Sendo assim, os processos de expansão e transformação urbana podem proporcionar baixa qualidade de vida a parcelas significativas da população, bem como impactos negativos ao meio ambiente em que estão inseridas.

Assim, a partir dos anos de 1980, começaram a surgir no Brasil os primeiros estudos referentes a mensuração da vulnerabilidade geotécnica dos solos nacionais. Isso se deu ao fato de que, historicamente, as áreas urbanas brasileiras sofrem frequentes problemas geotécnicos, estes decorrentes de processos erosivos e deslocamentos de massas de solos em áreas ocupadas por construções.

De acordo com Soares (2009), ainda que existam muitos estudos acerca da vulnerabilidade geotécnica de solos, poucos destes contemplam uma análise da distribuição e variação geográfica desta vulnerabilidade em unidades do terreno. Desta maneira, surgiram alguns trabalhos e pesquisam com o objetivo de representar, por meio de técnicas cartográficas (tais como mapas, sensoriamento remoto e geoprocessamento), a variação dos índices de susceptibilidade em ecossistemas determinados.

A representação da vulnerabilidade do solo por meio de técnicas de geoprocessamento e sensoriamento remoto caracterizam uma importante aplicação das chamadas geotecnologias no âmbito da Engenharia de Construção Civil e Urbana. Por meio destas aplicações, fica facilitada a compreensão de parâmetros geotécnicos relevantes no processo de planejamento, execução, ocupação e gestão territorial das áreas urbanas brasileiras (Braga, 2009).

No caso do município brasileiro de Uberlândia - MG, ainda não existem trabalhos em escala municipal que contemplem a análise geoespacial completa da vulnerabilidade geotécnica dos solos locais. Os poucos exemplares de pesquisas e experimentos realizados na área confluem apenas para o diagnóstico de categorias isoladas de vulnerabilidade do solo, sem promover inferências sobre possíveis causas e consequências, bem como relações de multilateralidade entre a ocorrência de processos erosivos e a dinâmica urbana municipal (Prefeitura Municipal de Uberlândia, 2015).

Portanto, neste cenário, compreender a vulnerabilidade ambiental e do solo de bacias hidrográficas urbanas se configura como importante mecanismo de análise dentro do âmbito da gestão e planejamento territoriais dos municípios brasileiros. Diante destes estudos, é possível aprimorar as técnicas de gerência do ambiente construído e ocupado pelo homem, de modo a buscar a prática consciente da urbanização e do desenvolvimento urbano sustentável das cidades no país.

\subsection{Caracterização da área de estudo}

O município de Uberlândia está localizado no estado de Minas Gerais, na região do Triângulo Mineiro e alto Paranaíba, entre as coordenadas geográficas $18^{\circ} 33^{\prime} 59.00^{\prime \prime}$ e $19^{\circ} 13^{\prime} 59.00^{\prime \prime}$ de latitude Sul, $47^{\circ} 02^{\prime} 59.00^{\prime \prime}$ e $48^{\circ} 49^{\prime} 59.00^{\prime \prime}$ e longitude Oeste, conforme pode ser visto na Figura 1. O território do município conta com uma superfície de 4.115,09 $\mathrm{Km}^{2}$ de extensão e possui uma população de, aproximadamente, 646.673 habitantes; de modo que sua densidade populacional é de $151,3 \mathrm{hab} / \mathrm{km}^{2}$ (IBGE - Instituto Brasileiro de Geografia e Estatística, 2013). 


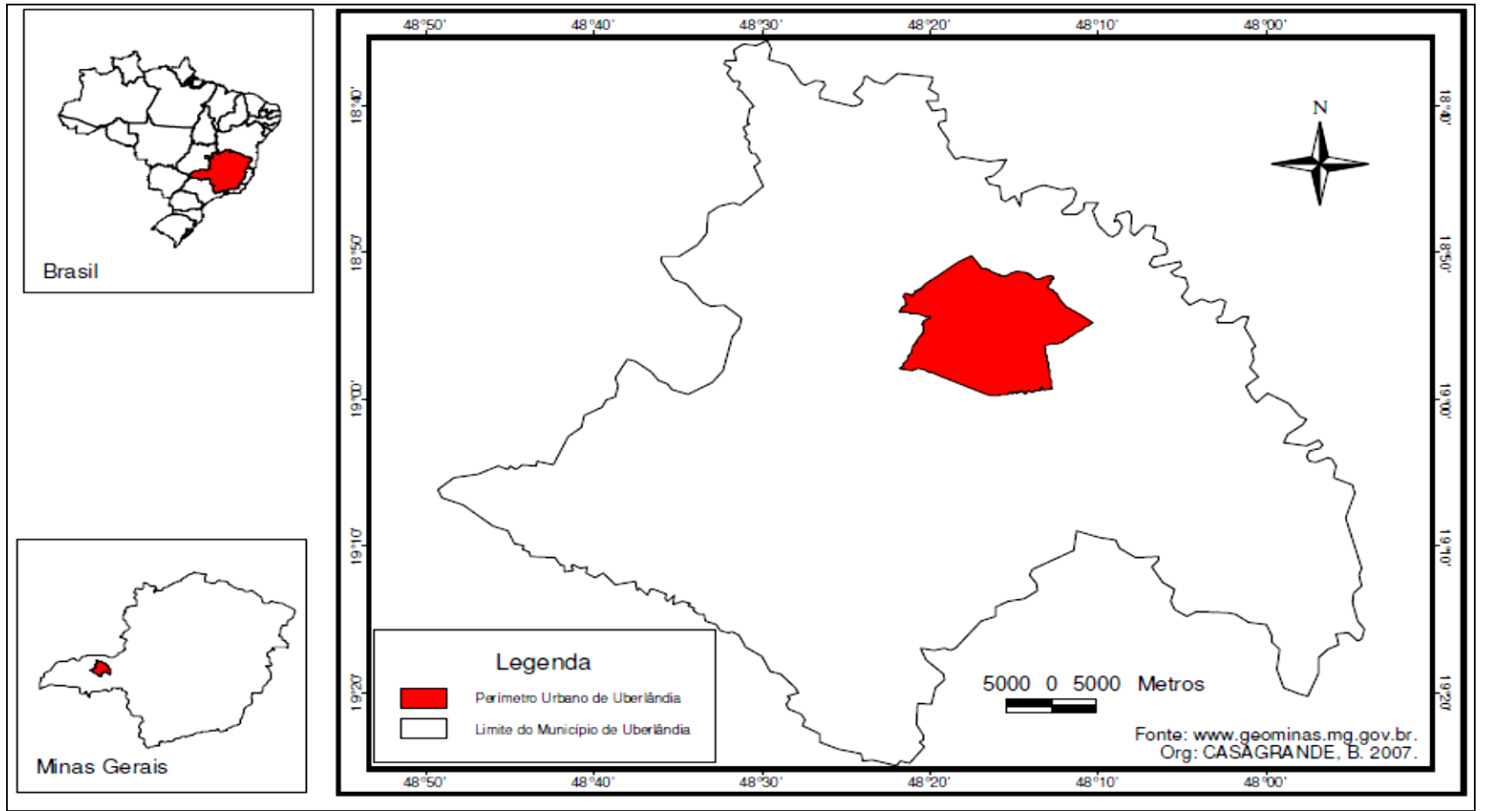

FIGURA 1: Mapa de localização do Município de Uberlândia - MG. FONTE: Prefeitura de Uberlândia Acervo digital (2015).

Segundo a Prefeitura Municipal de Uberlândia (2015), da área total do município, a área urbana ocupa apenas $219,00 \mathrm{~km}^{2}$. Os $3.896,09 \mathrm{~km}^{2}$ restantes são ocupados por áreas rurais, dominada principalmente pela pastagem e plantações de soja. Uberlândia é dividida em 05 Distritos: Uberlândia (Distrito sede), Cruzeiro dos Peixotos (24 km), Martinésia (32 km), Miraporanga (50 km) e Tapuirama (38 km). Faz divisa com os municípios de Araguari, Indianópolis, Monte Alegre de Minas, Prata, Tupaciguara, Uberaba e Veríssimo.

A Bacia Hidrográfica do Córrego Guaribas está localizada na porção Sudoeste (SO) da área urbana do município de Uberlândia, compreendida na zona do fuso 22. Ela se encontra entre as coordenadas geográficas $18^{\circ} 58^{\prime} 10,0^{\prime \prime} \mathrm{S}$ $48^{\circ} 17^{\prime} 35,48^{\prime \prime}$ W e $18^{\circ} 58^{\prime} 52,58^{\prime \prime} \mathrm{S}-48^{\circ} 21^{\prime} 16,04^{\prime \prime} \mathrm{W}$, apresentando uma área de aproximadamente 24,38 $\mathrm{km}^{2}$, fazendo parte da margem esquerda do rio Uberabinha. O Córrego Guaribas possui dez nascentes, sendo que três estão dentro do perímetro urbano e o restante está na zona rural do município (Figura 2).

De acordo com o zoneamento da Prefeitura Municipal de Uberlândia (2007), a Bacia Hidrográfica do Córrego Guaribas abrange além da zona rural do município, os bairros Jardim Canaã, Jardim Holanda, Jardim das Palmeiras II no setor oeste e, o bairro Nova Uberlândia, no setor sul do município. A estimativa populacional desses bairros é de aproximadamente 12.600 habitantes. Além disso, a bacia abrange ainda uma pequena parte dos bairros Jardim das Palmeiras e Chácaras Panorama (Figura 3).

Segundo Moura (2002), a ocupação dos bairros abarcados pelos limites da bacia se iniciou no final da década de 1980, com o intuito de construir moradias destinadas à população de baixa renda do município de Uberlândia. Atualmente, a Bacia Hidrográfica do Córrego das Guaribas é caracterizada pela expansão do programa governamental "Minha Casa, Minha Vida”, havendo grandes vazios urbanos destinados à agricultura familiar e pecuária devido a grande quantidade de chácaras e condomínios fechados também existentes na área de drenagem do córrego (Figuras 4 e 5).

No ano de 2006, foi criado próximo ao médio curso do Córrego Guaribas o loteamento Jardim das Palmeiras II, por iniciativa da Prefeitura Municipal de Uberlândia e da Secretaria de Habitação, em resposta ao Programa de Arrendamento Residencial (PAR) para pessoas de baixa renda. Foram construídas 500 unidades habitacionais, que começaram a ser habitadas em 2008. 


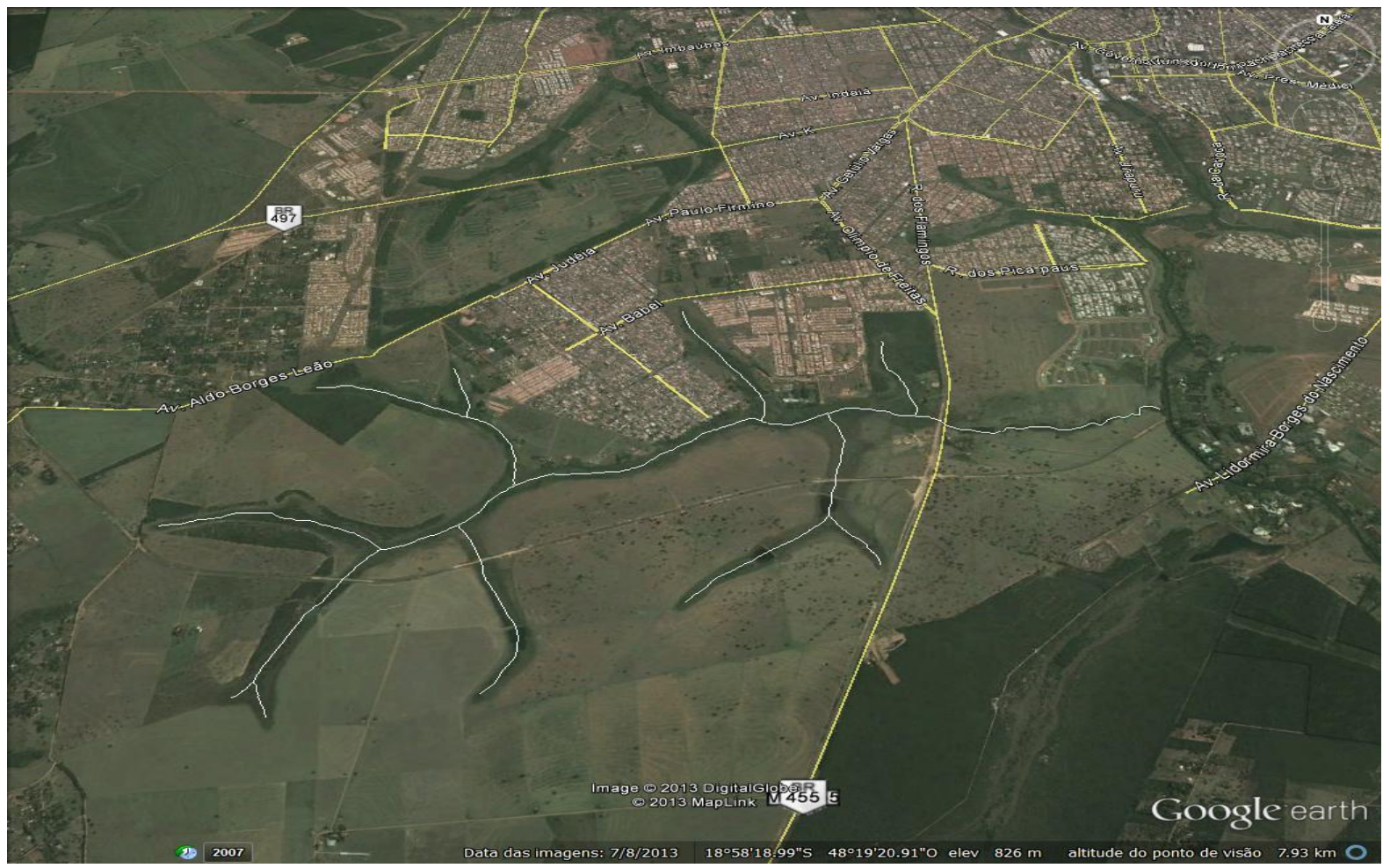

FIGURA 2: Bacia Hidrográfica do Córrego Guaribas e curso d’água.

FONTE: Google Earth (2011).

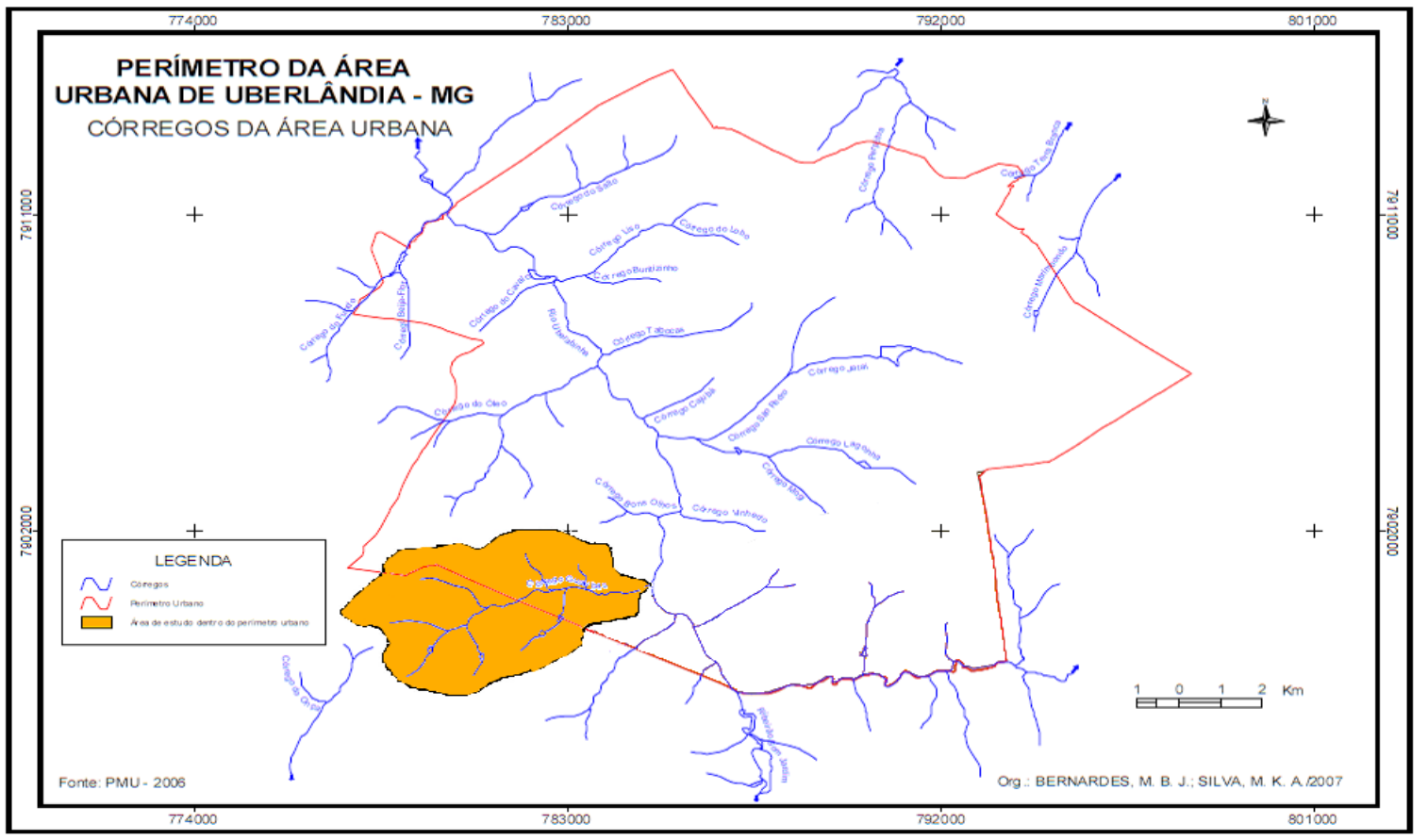

FIGURA 3: Localização da Bacia Hidrográfica do Córrego Guaribas (em laranja) dentro do perímetro urbano (em vermelho) do município de Uberlândia - MG.

FONTE: BERNARDES, 2007, modificado por PAVANIN, 2014. 


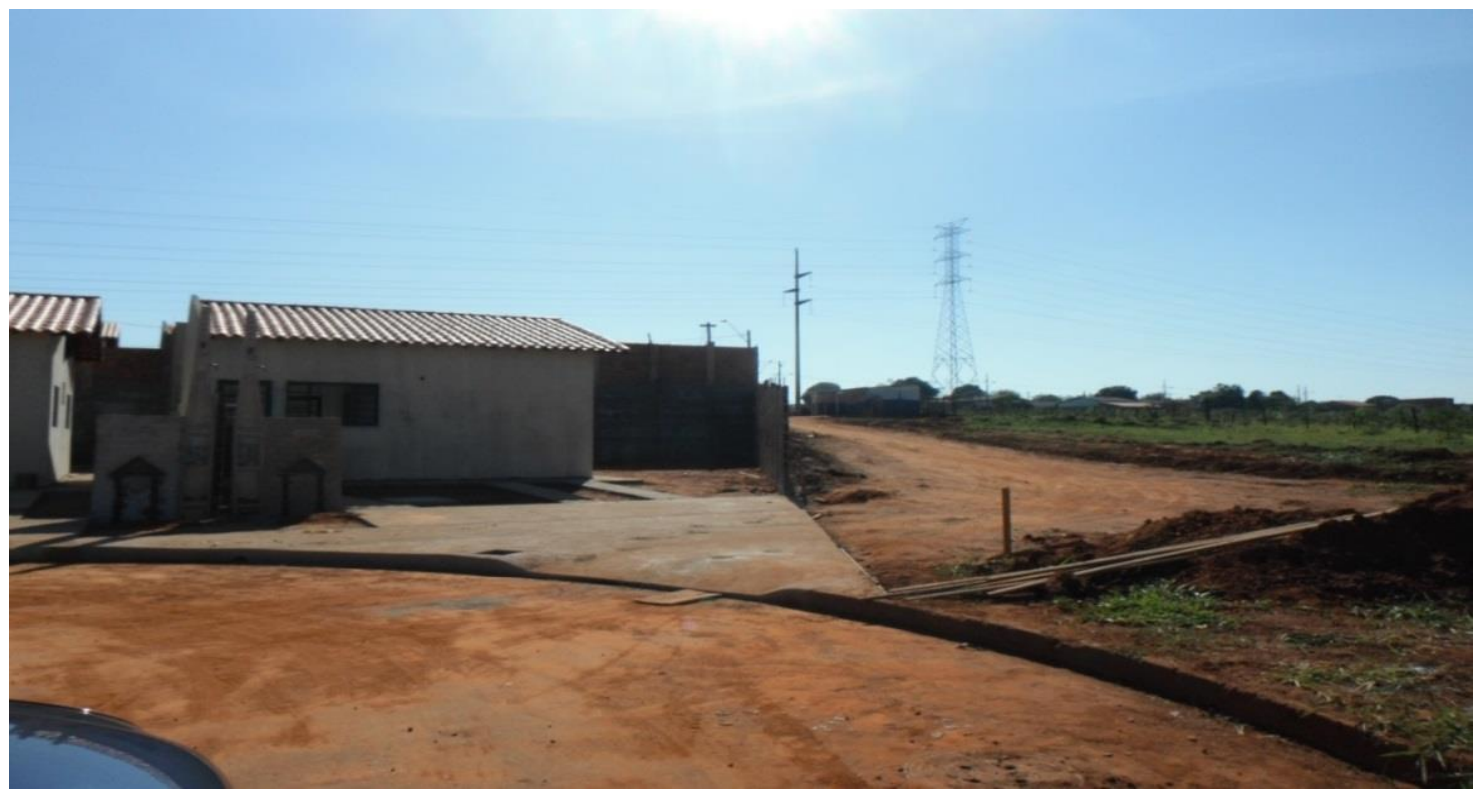

FIGURA 4: Programa "Minha casa, minha vida" no Bairro Jardim Canaã.

FONTE: Pavanin, 2014.

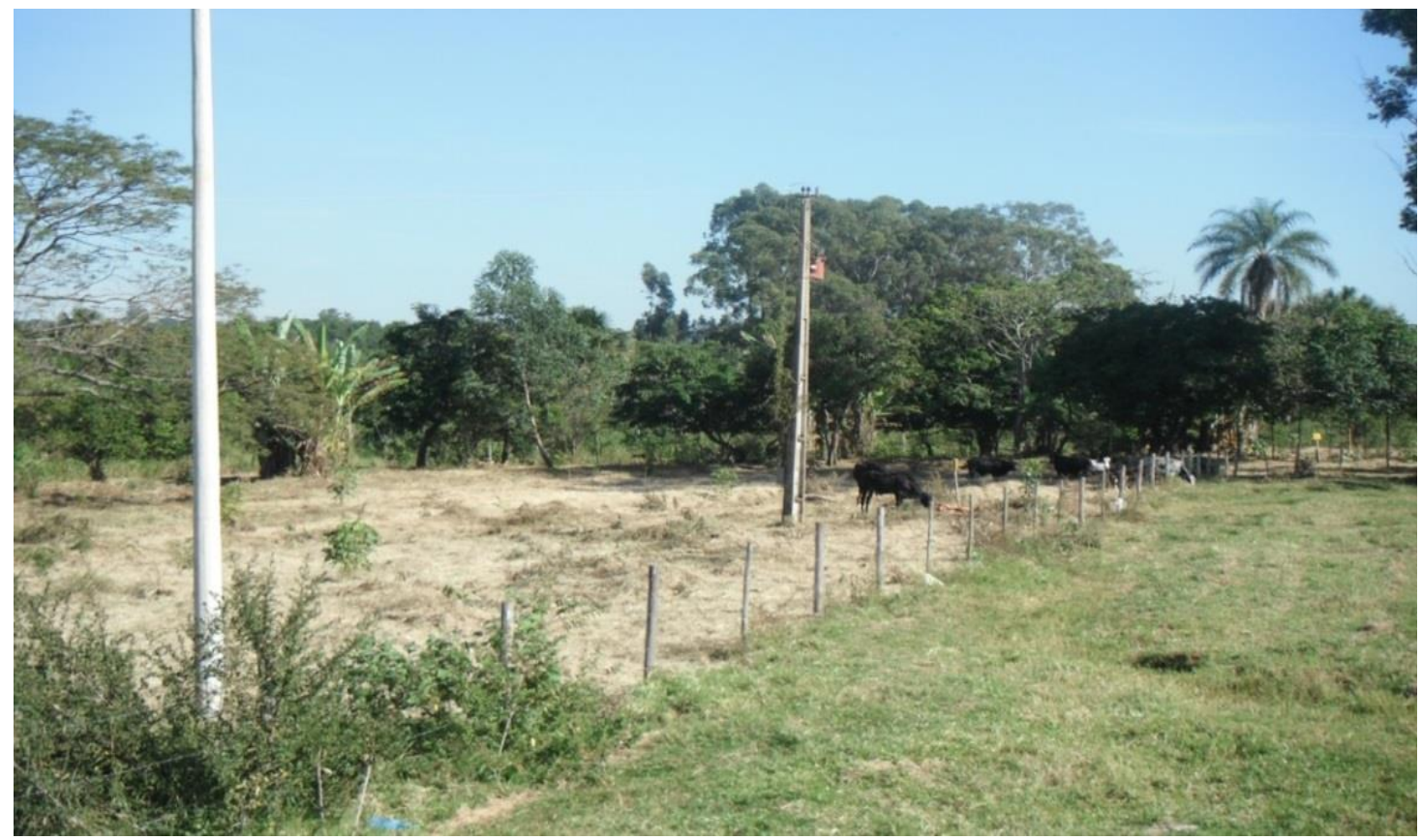

FIGURA 5: Local próximo ao perímetro urbano utilizado para pecuária.

FONTE: Pavanin, 2014.

Por fim, na área rural, a bacia ocupa 8,12 $\mathrm{km}^{2}$ e abrange quatro fazendas, sendo três de grande porte e destinadas à agricultura e pastagem. Existe ainda, a Fazenda São Bento, que possui dois galpões destinados à granja, além da criação gado de corte, distribuídos numa área de 31 alqueires. A fazenda ainda possui fossa e a captação de água é feita em uma das nascentes, através de uma bomba. Há ainda sete pequenas chácaras destinadas a moradia e passeio, onde a criação de gado e o cultivo de hortaliças são pouco expressivos.

\subsection{Análise de Multicritérios ou Álgebra de Mapas}

Este trabalho buscou aplicar a técnica de Análise de Multicritérios (ou AHP - Analystic Hierarchy Process) para elaborar um estudo acerca da vulnerabilidade à erosão do solo da Bacia Hidrográfica do Córrego Guaribas em Uberlândia MG. O termo Álgebra de mapas (AHP, ou Análise de Multicritérios) foi popularizado a partir do livro 
"Geographic Information System and Cartographic Modeling" (Tomlim, 1990). Esta foi a primeira abordagem em que se buscou explorar de uma maneira formal as propriedades dos dados representados em um Sistema de Informação Geográfica (SIG), usualmente representados por mapas.

De acordo com Tomlim (1990), o processo de Álgebra de Mapas (também conhecido como Análise de Multicritérios) pode ser entendido como a técnica na qual dados referentes a um determinado agente ou campo geográfico, representados sob a forma de diferentes variáveis e parâmetros, podem ser correlacionados por meio de instrumentos matemáticos e algébricos. Esta correlação gera como produto final uma sequência de mapas temáticos, tabelas, gráficos e outros instrumentos de interpretação visual que sintetizam a correlação entre os critérios que formam o SIG analisado (Figura 6).

Com base na aplicação da técnica AHP, buscou-se determinar um conjunto de variáveis e parâmetros que influenciassem de maneira significativa na ocorrência de processos e frentes erosivas na área de drenagem do Córrego Guaribas. Foram eleitos quatro parâmetros que, posteriormente, foram organizados na forma de um SIG - Sistema de Informação Geográfica, e manipulados numericamente de forma a lhe serem atribuídos valores quantitativos. Estes valores, posteriormente e por meio da utilização de técnicas e softwares de geoprocessamento, puderam ser correlacionados e originaram o mapa final de vulnerabilidade do solo da área de estudo. O detalhamento deste processo encontra-se exposto na seção que se segue.

Desta maneira, por fim, aplicou-se o processo de Análise de Multicritérios para realizar o diagnóstico final da vulnerabilidade do solo da Bacia Hidrográfica do Córrego Guaribas em Uberlândia MG. Os resultados obtidos por meio da metodologia exposta encontram-se na seção que se segue.

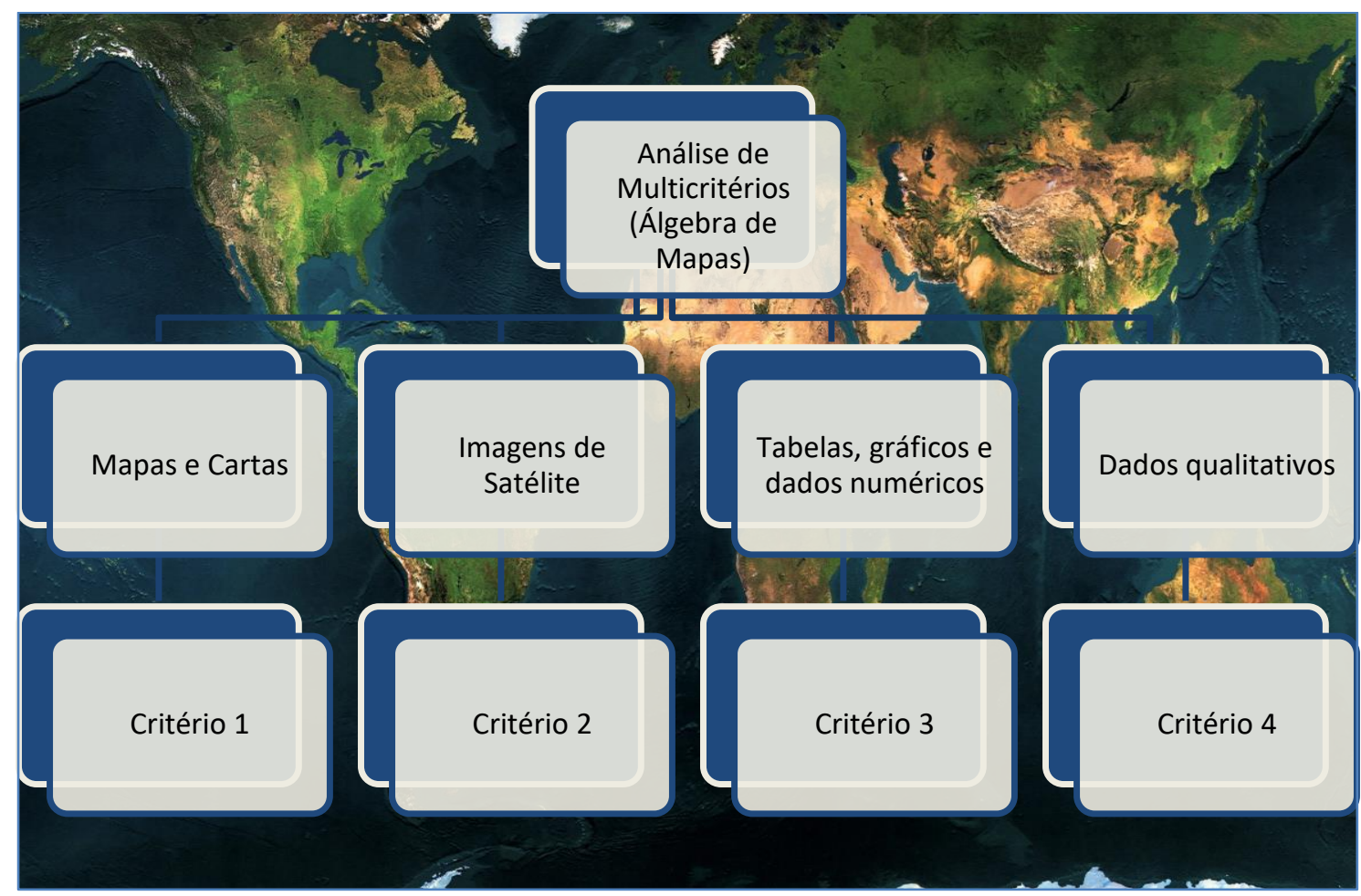

FIGURA 6: Hierarquia básica da Análise de Multicritérios ou Álgebra de Mapas. FONTE: Autores. 


\subsection{Elaboração do Sistema de Informação Geográfica (SIG)}

A elaboração dos mapas de vulnerabilidade do solo da Bacia Hidrográfica do Córrego Guaribas só foi possível mediante a elaboração prévia de um SIG digitalizado com informações e dados com referenciais geográficos precisos a respeito da área de estudo. Para tanto, buscou-se discriminar quais seriam as principais variáveis e parâmetros informativos que influenciariam de maneira significativa na potencialidade de erosão e vulnerabilidade do solo local.

Desta maneira, escolheram-se os seguintes parâmetros para servirem como base do banco de dados do SIG:

- Dinâmica de uso e ocupação do solo da área de estudo;

- Topografia, relevo e declividade da bacia hidrográfica;

- $\quad$ Classes de material inconsolidado existente no local;

- $\quad$ Profundidade do nível d'água.

\subsection{Estudo de uso e ocupação do solo}

Para o estudo da dinâmica de uso e ocupação do solo da área da bacia, buscou-se promover a compilação dos mapas de uso e ocupação do solo local, referentes ao ano de 2013. Para tanto, foram utilizadas um número desconhecido de imagens de vários satélites, oriundas do software livre GoogleEarth, versão profissional.

Assim, foram utilizadas imagens de satélite para a delimitação da área Bacia Hidrográfica do Córrego Guaribas em conjunto com as cartas topográficas editadas pelo Ministério do Exército-Departamento de Engenharia e Comunicação MI-2488/1-NE e MI-2451/3-SE Uberlândia, na escala 1:25.000, já digitalizadas pelo Instituto de Geografia da Universidade Federal de Uberlândia (IGUFU). Dessa forma, observando as marcações das curvas de nível das referidas cartas e com o auxílio do software livre SPRING, disponibilizado pelo INPE (Instituto Nacional de Pesquisas Espaciais), delimitou-se a área referente à Bacia Hidrográfica do Córrego Guaribas (Figura 7).

A metodologia para a caracterização e mapeamento de categorias de uso do solo baseouse em

Rosa (2005), que define as seguintes etapas:

- $\quad$ Elaboração de um mapa base que contenha os limites da área de estudo, drenagem, coordenadas, rodovias etc;

- Elaboração de uma chave de fotointerpretação;

- Interpretação visual preliminar das imagens, podendo assim estabelecer uma associação entre o que se identificou nas imagens, com as correspondentes unidades existentes no terreno.

Com a aplicação desta metodologia, estabeleceu-se parâmetros para categorizar as classes de uso e ocupação do solo local, mediante a correlação entre estes parâmetros e o banco de dados de imagens de satélite obtidos via Google Earth. A correlação destes dados se deu mediante, novamente, a utilização da plataforma SPRING para obtenção de uma interface digitalizada e infográfica dos mapas temáticos estabelecidos. Terminada esta etapa de análise e geoprocessamento, elaborou-se - mapa de uso e ocupação do solo da Bacia Hidrográfica do Córrego Guaribas em 2013(Figura 8).

Todos os tipos de usos e ocupações do solo presentes no mapa de 2013 receberam pesos indicando o seu grau de fragilidade. Nesse sentido, situações agravantes observadas nos trabalhos de campo empreendidos foram apontadas, agregando valores atribuídos aos pesos, como demonstrado no Quadro 1, os quais resultaram em alguns casos, na mudança de uma classe de fragilidade inicialmente menor, para outra classe superior. 


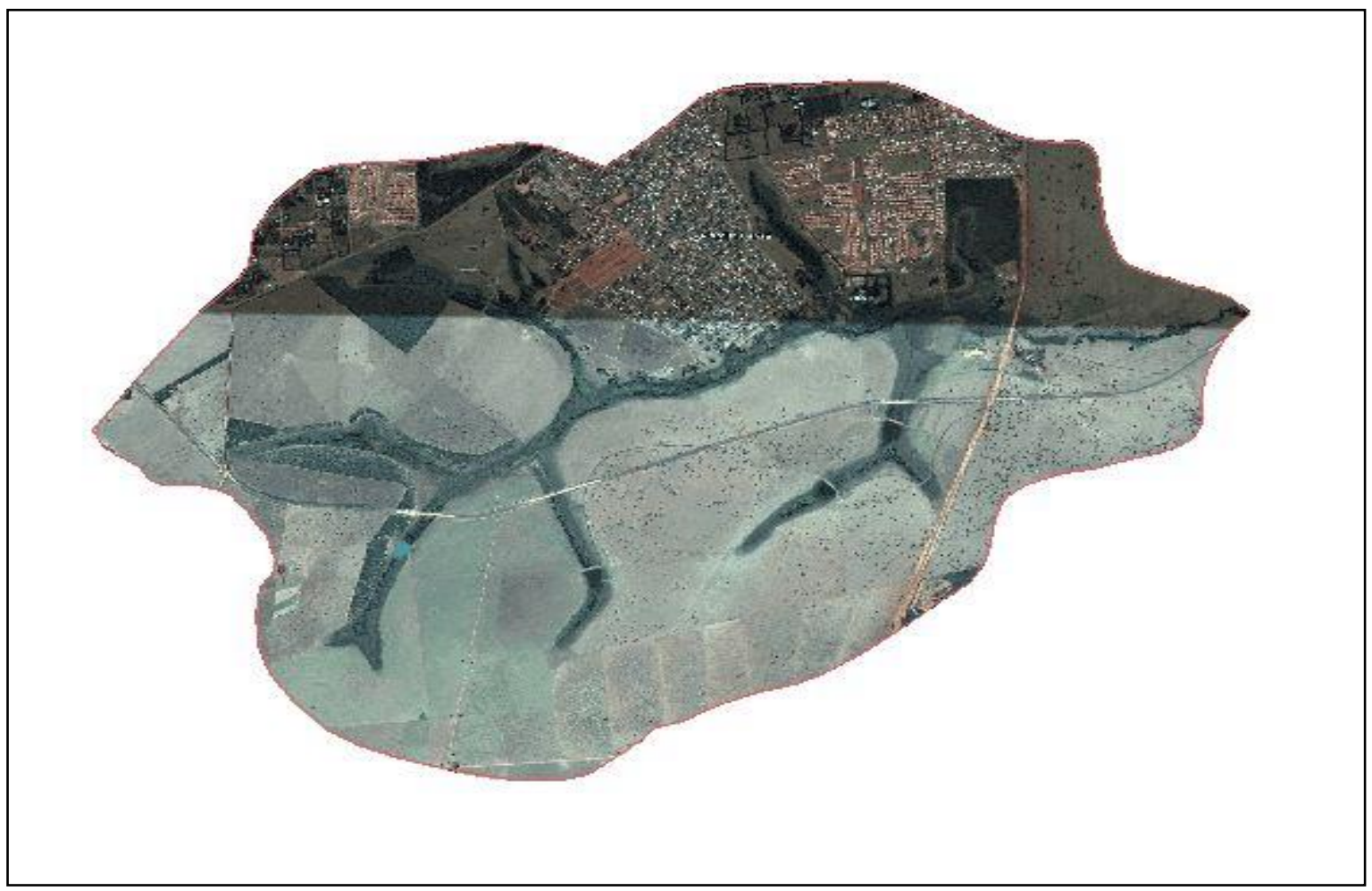

FIGURA 7: Área da Bacia Hidrográfica do Córrego Guaribas. FONTE: Autores.

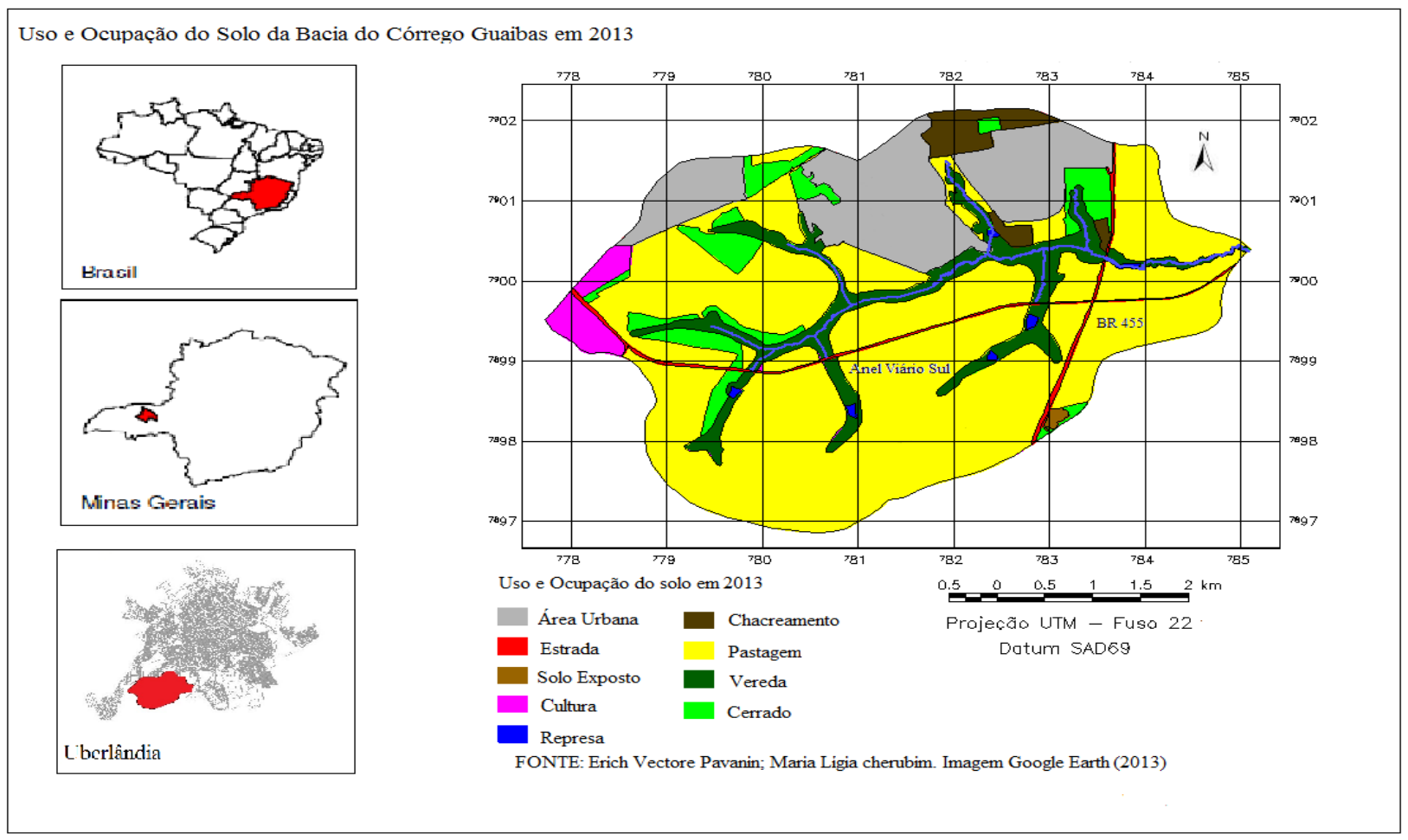

FIGURA 8: Uso e ocupação do solo da Bacia Hidrográfica do Córrego Guaribas em 2013. FONTE: Pavanin, 2013. 
QUADRO 1: Vulnerabilidade e Uso e Ocupação do Solo.

\begin{tabular}{|c|c|c|c|c|}
\hline Uso e ocupação & $\begin{array}{l}\text { Fragilidade à } \\
\text { erosão }\end{array}$ & Peso numérico & Agravantes & Adicionais dos agravantes \\
\hline \multirow{4}{*}{ Vereda } & \multirow{4}{*}{ Média } & \multirow{4}{*}{3} & Represas & 0,5 \\
\hline & & & APPs irregulares & 0,5 \\
\hline & & & Área urbana próxima & 1 \\
\hline & & & Esgoto & 0,5 \\
\hline \multirow[t]{3}{*}{ Cerrado } & \multirow{3}{*}{ Média } & \multirow{3}{*}{3} & $\begin{array}{c}\text { Ausência de áreas de } \\
\text { amortecimento }\end{array}$ & 0,5 \\
\hline & & & Área urbana próxima & 1 \\
\hline & & & Isolamento & 0,5 \\
\hline \multirow[b]{2}{*}{ Pastagem } & \multirow{2}{*}{ Baixa } & \multirow{2}{*}{2} & Pastagem degradada & 1 \\
\hline & & & Pastagem com manejo & 0 \\
\hline \multirow[b]{2}{*}{ Cultura } & \multirow{2}{*}{ Baixa } & \multirow{2}{*}{2} & Cultura anual & 1 \\
\hline & & & Cultura perene & 0 \\
\hline \multirow{7}{*}{ Área urbana } & \multirow{7}{*}{ Muito baixa } & \multirow{7}{*}{1} & Solo exposto & 1 \\
\hline & & & Solo impermeabilizado & 1 \\
\hline & & & $\begin{array}{c}\text { Alta densidade } \\
\text { populacional }\end{array}$ & 1 \\
\hline & & & $\begin{array}{c}\text { Baixa densidade } \\
\text { populacional }\end{array}$ & 0 \\
\hline & & & Infraestrutura básica & 0 \\
\hline & & & Falta de infraestrutura & 1 \\
\hline & & & Criação de rebanho & 1 \\
\hline
\end{tabular}

No presente estudo foi considerado que, os usos que possuem elevados valores de impacto ambiental, como, por exemplo, a urbanização, terão um grau de fragilidade inicialmente baixo, pois teoricamente, os ambientes urbanos são tão modificados que acabam por diminuir sua fragilidade inicial por já se encontrarem impactados e, de algum modo, adaptados a essa condição. Por outro lado, usos que ainda possuem baixos índices de impactos ficarão em uma situação de possível fragilidade, sendo esta intensificada pelos agravantes.

\subsection{Estudo da declividade e relevo}

Para a determinação dos parâmetros topográficos e de relevo da Bacia Hidrográfica do Córrego Guaribas, utilizou-se como elemento básico de interpretação o mapa de declividade disponibilizado pela Prefeitura Municipal de Uberlândia (Figura 9). Assim, buscou-se atribuir diferentes valores de peso numérico para as variações de declividade na área da bacia para auxiliar na compreensão e estudo da vulnerabilidade do solo à erosão dentro de parâmetros numéricos. A quantificação destes pesos para as diferentes variações de declividade indica que quanto maior for esse valor numérico de peso maior será sua contribuição para o aumento da fragilidade ambiental e vulnerabilidade deste solo à erosão (Quadro 2).

Para a atribuição destes pesos, foram considerados três fatores expostos por Grosh \& e Jarret (1994), que podem acarretar na erosão do solo, sendo eles:

- Aumento no desprendimento de partículas de solo provocado pelo maior ângulo de impacto das gotas da chuva sobre a superfície do solo;

- Maior facilidade com que as partículas se movimentam no sentido da declividade pelo efeito da gravidade, para maiores declividades da superfície do solo;

- Aumento da velocidade de escoamento superficial, o qual amplia a capacidade de transporte do escoamento. 


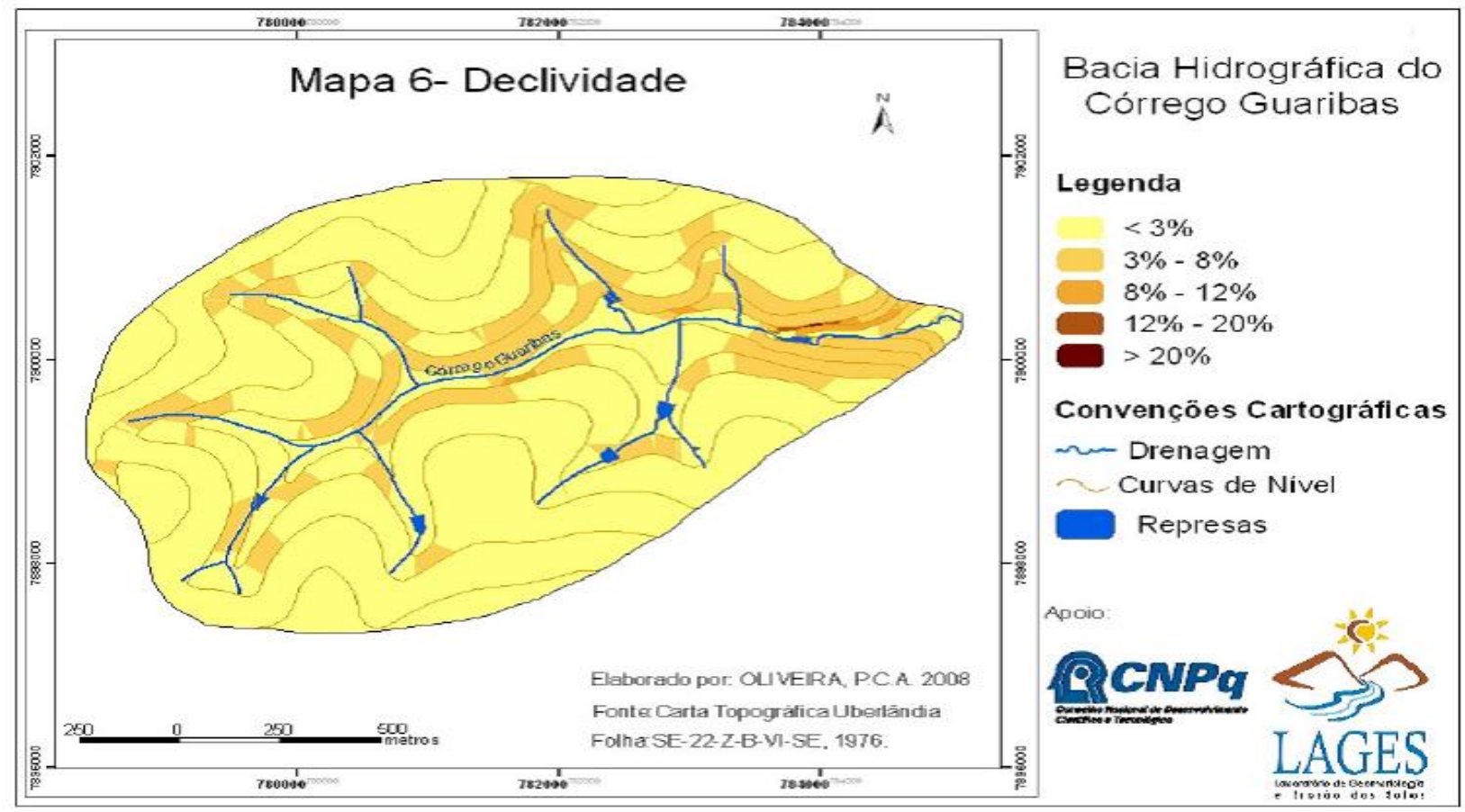

FIGURA 9: Mapa de declividade do solo da Bacia.

FONTE: Carta Topográfica de Uberlândia, 1976.

\begin{tabular}{|c|c|c|}
\hline \multicolumn{2}{|c|}{ QUADRO 2: Vulnerabilidade e declividade do solo } \\
\hline Intervalo de declividade & Vulnerabilidade & Peso \\
\hline$<3 \%$ & Muito baixa & 2 \\
\hline 3 a $8 \%$ & Baixa & 3 \\
\hline 8 a $12 \%$ & Média & 4 \\
\hline 12 a $20 \%$ & Alta & 5 \\
\hline$>20 \%$ & Muito alta & \\
\hline
\end{tabular}

\subsection{Estudo da composição geotécnica do solo}

Em relação ao material inconsolidado da área de drenagem do Córrego Guaribas, foram avaliadas características referentes à granulometria de cada tipo de unidade, fato que foi determinante para o estabelecimento das classes de fragilidade das mesmas. Dentro dessa lógica, foi pensado que, no caso da erosão do solo, quando maior for à quantidade de arenitos da fração areia presentes na constituição de determinado tipo de solo, maior será seu peso e consequentemente mais critica será sua classe de fragilidades (Quadro 3).

Considerou-se, desta forma, que quanto maior a presença de arenitos da fração areia na constituição de determinado tipo de solo, maior a sua vulnerabilidade a erosão. Isto ocorre visto que os solos arenosos, com espaços porosos maiores, durante uma chuva de pouca intensidade, pode absorver toda água, não havendo nenhum dano. $\mathrm{Na}$ área da bacia do córrego das Guaribas, constatou-se que os solos de origem basáltica (Formação Serra Geral) são pouco comuns, ocupando apenas o equivalente a $2,5 \%$ da área total dentro do limite da bacia.Os solos da formação Marília ocupam a maior parte da área, $86 \%$ do total. Os solos hidromórficos, são encontrados exclusivamente onde há veredas, ocupando $8 \%$ da área total. Os solos do tipo Colúvio Serra Geral e Marilia, ocupam aproximadamente $3,5 \%$ da área total da bacia do córrego das Guaribas.

\subsection{Estudo da profundidade do nível d'água}

Com relação à profundidade do nível de água, os pesos e classes de fragilidade foram 
atribuídos considerando que, quanto mais raso o nível da água, maior será sua influência sobre os processos erosivos e de contaminação das águas do córrego, logo possuirá um valor de vulnerabilidade maior. Dentro dessa lógica e das profundidades identificadas no limite da bacia do Córrego das Guaribas, foi considerado que as áreas possuidoras de lençóis d'água com profundidades inferiores a 2 metros, estrão em uma condição de extrema fragilidade, logo possuirão o peso máximo tanto em relação à vulnerabilidade a erosão quanto à contaminação química da água. Já as localidades onde a profundidade é superior a 20 metros, estão em uma condição de fragilidade muito baixa e possuíram um peso muito baixo, como demonstrado pelo Quadro 4.

\section{RESULTADOS E DISCUSSÕES}

Considerando o somatório dos pesos de fragilidade para cada atributo, os mapas de declividade, uso e ocupação, materiais inconsolidados e profundidade do nível de água foram sobrepostos por meio da aplicação de técnicas de geoprocessamento. Desta maneira, gerou-se o mapa de vulnerabilidade ambiental do solo à erosão para o ano de 2013 (Figura 10), identificando cinco classes de fragilidade com intervalos diferentes para cada mapa:

- Vulnerabilidade Muito Baixa: corresponde a valores $\leq 5$;

- Vulnerabilidade Baixa: corresponde a todos os valores entre o intervalo $5<X \leq 8$;

- Vulnerabilidade Média: corresponde a todos os valores entre o intervalo $8<X \leq 12$;

- Vulnerabilidade Alta: corresponde a todos os valores entre o intervalo $12<X \leq 15$;

- Vulnerabilidade Muito Alta: corresponde a todos os valores entre o intervalo15 $<\mathrm{X} \leq$ 19.

Assim, com base na interpretação dos mapas previamente elaborados e tabelas anteriormente expostas, elaborou-se uma tabela matriz contendo os valores numéricos referentes aos valores de vulnerabilidade do solo da área da bacia (Quadro 5) a fim de facilitar a compreensão destes processos.

QUADRO 3: Formação geomorfológica da área do Córrego Guaribas.

\begin{tabular}{|c|c|c|}
\hline Tipo de formação & Vulnerabilidade & 1 \\
\hline Residuais da Serra Geral & Muito baixa & 2 \\
\hline Colúvio Serra Geral e Marília & Baixa & 2 \\
\hline Hidromórficas & Baixa & 4 \\
\hline
\end{tabular}

FONTE: Autores.

QUADRO 4: Profundidade e vulnerabilidade do nível d'água na bacia.

\begin{tabular}{|c|c|c|}
\hline Profundidade & Vulnerabilidade & Peso \\
\hline Inferior a 2 metros & Muito alta & 4 \\
\hline Entre 2 e 5 metros & Alta & 3 \\
\hline Entre 5 e 10 metros & Média & 2 \\
\hline Entre 10 e 20 metros & Baixa & 1 \\
\hline Maior que 20 metros & Muito baixa & \\
\hline
\end{tabular}




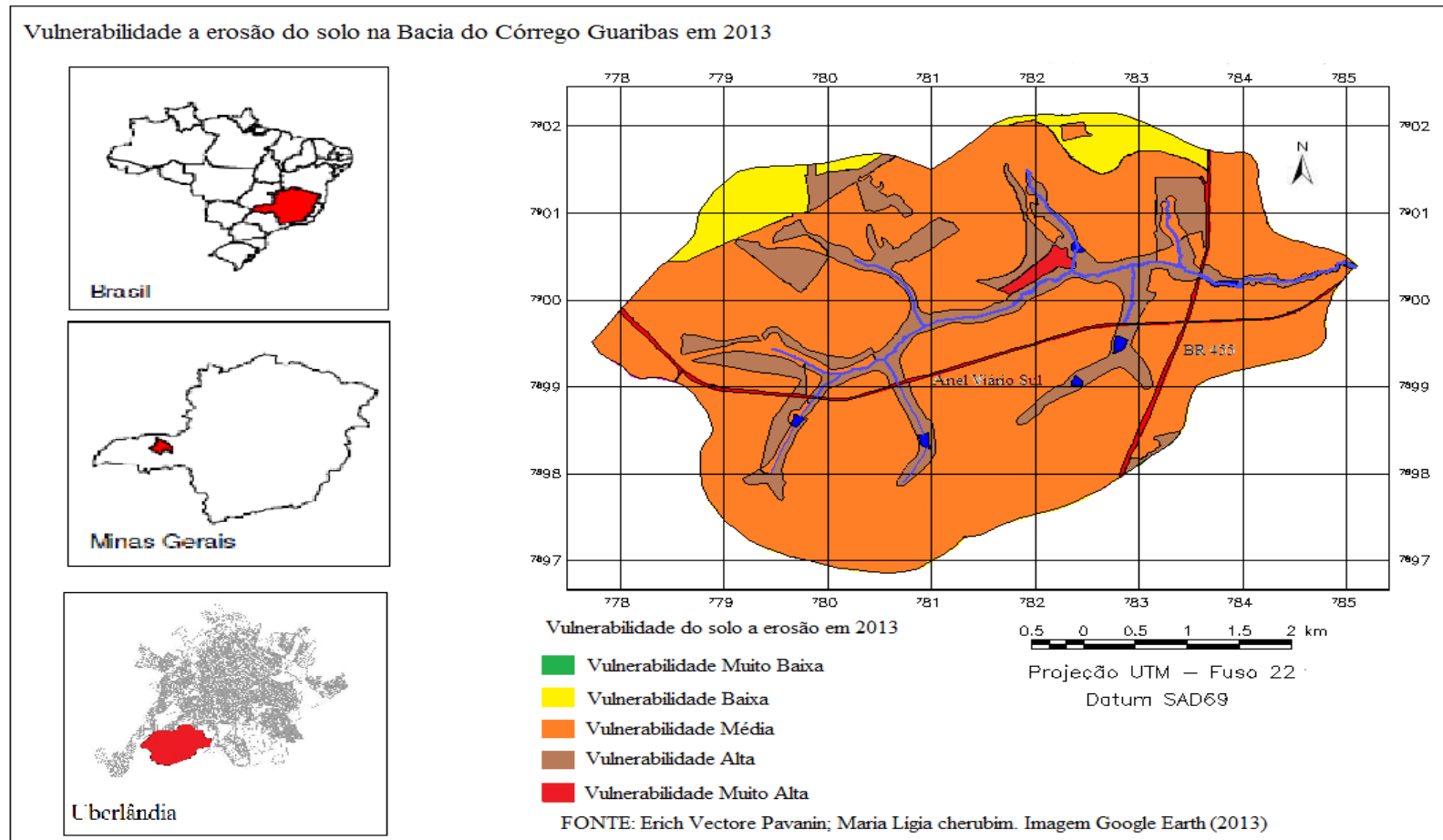

FIGURA 10: Mapa de vulnerabilidade à erosão do solo na Bacia Hidrográfica do Córrego Guaribas. FONTE: Adaptado de Pavanin (2013).

QUADRO 5: Valores das diferentes classes de vulnerabilidade do solo no Córrego Guaribas.

\begin{tabular}{|c|c|c|}
\hline \multirow{2}{*}{ Vulnerabilidade } & \multicolumn{2}{|c|}{$\mathbf{2 0 1 3}$} \\
\cline { 2 - 3 } & Área $\left(\mathrm{km}^{2}\right)$ & Área (\%) \\
\hline Muito alta & 0,240636 & 1,7 \\
\hline Alta & 3,489230 & 14,5 \\
\hline Média & 18,047745 & 74,3 \\
\hline Baixa & 2,286047 & 9,5 \\
\hline Muito baixa & 0 & 0 \\
\hline TOTAL & 24,06366 & 100 \\
\hline
\end{tabular}

Assim, os dados expressos no Quadro 5 mostram que, da totalidade da área da bacia, apenas 1,7\% apresentam índices de vulnerabilidade classificados como muito altos. Esta elevada fragilidade é decorrente de vários fatores, tais como a baixa profundidade do lençol de água, o tipo de material inconsolidado (solos residuais da formação Marília) e anormalidades presentes no uso e ocupação (casas e criação de dentro da área de APP).

Além disso, os usos e ocupações identificados na área em vermelho na Figura 10 foram os de Mata Ciliar e área Urbana. Neste cenário, estas áreas tiveram os seus valores de vulnerabilidade do solo elevados pela presença de vários agravantes, tais como lançamento direto de esgotos e águas pluviais, ausência de APPs devidamente regularizadas, de acordo com os padrões estabelecidos em legislações ambientais, presença de vários tipos de animais (aves, suínos, equinos e bovinos) dentro das APPs e proximidade com a área urbana.

Assim, pode-se dizer que tal cenário do uso e ocupação se constitui, atualmente, como o principal agravante para esse elevado índice de vulnerabilidade. Além disso, as áreas classificadas 
com índices de vulnerabilidade altos ocupam aproximadamente $14,5 \%$ da área total da bacia do Córrego das Guaribas. Essa classe de vulnerabilidade se associa as áreas identificadas como veredas e remanescentes de cerrado no mapa de uso e ocupação. Contudo, há uma parcela de área urbana, representada pelo bairro Jardim Canaã, que devido a certos agravantes, como a presença de infraestruturas precárias e/ou a falta delas e a alta densidade populacional, agregaram valores que aumentaram a classificação da vulnerabilidade, passando de um tipo de uso e ocupação do solo inicialmente associado a valores muito baixos de vulnerabilidade, para valores elevados.

A vulnerabilidade classificada como média foi identificada em cerca de $75,0 \%$ da área total da bacia. Tal classe está associada principalmente, aos Residuais da Formação Marília. A susceptibilidade natural dessa unidade superficial aos processos erosivos é agravada pelo tipo de ocupação que a área possui, predominantemente de criação de bovino e áreas urbanas. A vulnerabilidade mediana é constatada em alguns pontos dentro da vereda, principalmente, onde ainda há remanescentes de cerrados próximos, os quais acabam por assumir a função de áreas de amortecimento, que por sua vez minimizam o cenário de alta vulnerabilidade, presente nesse tipo de uso e ocupação do solo.

A baixa vulnerabilidade aos processos erosivos foi encontrada em $9,5 \%$ da área total da bacia, exclusivamente, onde há ocupação urbana. Essa classe se relaciona a declividades relativamente baixas (inferior a 8\%) e a elevada profundidade do nível do lençol freático, no caso entre 10 e 20 metros de profundidade.

Por fim, não foi possível identificar neste estudo áreas com vulnerabilidades muito baixas em relação à erosão do solo, em decorrência do próprio tipo de solo predominante na área pesquisada. Hipoteticamente, esse cenário de vulnerabilidade muito baixa só seria possível em declividades menores que $3 \%$, com solos residuais da formação Serra Geral, profundidade do lençol superior a 20 metros e a área urbana como uso e ocupação do solo sem nenhum agravante.

\section{CONCLUSÕES}

Conhecer os níveis de vulnerabilidade ambiental decorrentes da expansão urbana na bacia do Córrego das Guaribas foi o objetivo proposto pelo presente estudo. Com esta premissa, o trabalho aqui desenvolvido lançou luzes sobre vários aspectos que devem ser priorizados, quando a preservação do ambiente e a relação harmônica do homem e a natureza são entendidos como um compromisso de todos. Nesse sentido, vale destacar que a bacia do Córrego Guaribas já possuía uma predisposição para a vulnerabilidade ambiental, oriunda de fatores naturais (declividade e solo). Esta predisposição, somada às atividades de origem antrópica, aumentaram os níveis de vulnerabilidade à erosão do solo dentro dos limites dessa bacia.

O mapeamento da vulnerabilidade ambiental relacionada à erosão do solo indicou que a maior parte da bacia possui uma vulnerabilidade natural relacionada aos arenitos da Formação Marília, que quando associada ao presente tipo de uso e ocupação do solo resultou em valores maiores de vulnerabilidade. É interessante constatar que usos relacionados a valores de vulnerabilidade baixos, como as pastagens e as áreas urbanas podem adicionar agravantes, devido ao manejo descuidado dessas atividades, contribuindo para a elevação do seu grau de vulnerabilidade.

Este trabalho identificou que as áreas de vereda, além de possuir um uso e ocupação bem vulnerável, essas sofreram e sofrem as influências das áreas urbanas próximas, em especial as que invadem a faixa que originalmente deveria ser utilizada como APP, da falta de áreas de amortecimento no seu entorno, sendo diretamente expostas as áreas utilizadas pela urbanização e pela pastagem, fatores somados a elevada declividade que essas áreas possuem.

Outro aspecto que deve ser considerado refere-se aos remanescentes de Cerrado, que possuem como principal agravante, além de estarem cercados por áreas urbanas ou por pastagem, o fato de se encontrarem isolados uns dos outros. Tal problema embora não seja muito significativo no curto prazo, ao longo do tempo 
pode resultar na diminuição da resistência das espécies nativas deixando-as mais vulneráveis às doenças e consequentemente, diminuindo drasticamente a fauna e flora dessa região.

Por fim, este trabalho conseguiu diagnosticar a importância da elaboração de estudos quantitativos para análise da vulnerabilidade ambiental do ambiente construído e ocupado pelo homem. Com estes estudos, realizados mediante a aplicação de Geotecnologias e técnicas de geoprocessamento, é possível estabelecer parâmetros importantes para o processo de tomada de decisão dentro do âmbito da gestão territorial e ambiental, de forma a contribuir significativamente para a efetivação de políticas e ações de Engenharia de Construção Civil e Urbana que visem o desenvolvimento pleno das atividades humanas e sua concomitância com a preservação dos recursos naturais existentes na Biosfera.

\section{AGRADECIMENTOS}

Agradecemos à Universidade Federal de Uberlândia (UFU), bem como à Faculdade de Engenharia Civil (FECIV), o Instituto de Geografia (IGUFU), à Pró-Reitoria de Pós Graduação e Pesquisa (PROPP) e à Prefeitura Municipal de Uberlândia, instituições estas que foram fundamentais e nos ampararam durante a execução deste trabalho.

\section{REFERÊNCIAS BIBLIOGRÁFICAS}

BERNARDES, M. B. J. Bacia Hidrográfica de Rio Uberabinha: A Disponibilidade de Água e o Uso do Solo sob a Perspectiva da Educação Ambiental. Disponível em

http://www.bdtd.ufu.br/tde_arquivos/MBJBernardesTE S01PRT.pdf> Acesso em 31 de Outubro de 2011.

BRAGA, R. Planejamento urbano e recursos hídricos. Rio Claro: Laboratório de Planejamento Municipal- IGCE UNESP. 2003. p.113-127.

BRASIL. Resolução CONAMA $\mathbf{N}^{\circ} \mathbf{3 0 3}$, de $\mathbf{2 0}$ de março de 2002. Dispõe sobre parâmetros, definições e limites de áreas de preservação permanente. Disponível em: <http://www.mma.gov.br/port/conama/res/res02/res3 0302.html>. Acesso: abril/2016.
COSTA, F. P. M.; NISHIYAMA, L. Utilização do Permeâmetro Guelph e Penetrômetro de Impacto em Estudos de Uso e Ocupação dos Solos em Bacias Hidrográficas. Revista Caminhos de Geografia, Instituto de Geografia da Universidade Federal de Uberlândia. Uberlândia, 2007.

GOOGLE EARTH. 2012. Imagens GEOEYE da região da Bacia do Córrego Barbosa localiza na cidade de Uberlândia-MG referentes ao ano de 2011.

INPE. 2012. Spring. Disponível em: <http://www.dpi.inpe.br/spring/ >. Acesso em: mar. 2012.

Instituto Brasileiro de Geografia e Estatística (IBGE). Censo demográfico 2013. Rio de Janeiro: IBGE, 2014. Disponível em: <http://www.ibge.gov. $\mathrm{br} /$ cidadesat/topwindow.htm?1>. Acesso em: mar. 2014.

MOURA, G. G. Imagens e representações da periferia de Uberlândia (MG): um estudo de caso do setor Oeste. Dissertação (Mestrado) 284 fls. Instituto de Geografia. Universidade Federal de Uberlândia, Uberlândia, 2002.

SOARES, A. M.; CUNHA, D. A. I.; DANTAS, G. D.; OLIVEIRA, H. L. P. Bacia Hidrográfica do Córrego Lagoinha,

Uberlândia-MG: desafios do planejamento urbano. Revista da Católica, Uberlândia, v. 1, n. 1, p. 103-115, $2009 . \quad$ Disponível em: $<$ www.catolicaonline.com.br/revistadacatolica $>$. Acesso: jun/2012.

NISHIYAMA, L. Geologia do município de Uberlândia e áreas adjacentes. Sociedade e Natureza. Uberlândia. EDUFU, no 1, p.9-16, jun. 1989.

OLIVEIRA, P. C. A. Cenários Ambientais e Diagnose da Bacia Hidrográfica do Córrego Guaribas, UberlândiaMG. Universidade Federal de Uberlândia (UFU), Programa de Pós-Graduação em Geografia. 2009.

PREFEITURA MUNICIPAL DE UBERLÂNDIA. Secretaria de Planejamento Urbano. Mapas de Uberlândia. Disponível em:

http://www.uberlandia.mg.gov.br/2014/secretariapagi na/56/134/mapas_de_uberlandia.html >. Acesso: Out. 2015 .

PAVANIN, E. V.; \& CHUERUBIM, M. L. Diagnóstico ambiental da bacia hidrográfica do córrego Guaribas no município de Uberlândia-MG. In: XXVI Congresso Brasileiro de Cartografia V Congresso Brasileiro de Geoprocessamento XXV Exposicarta, 2014, Gramado.

ROSA, R. Geotecnologias na geografia aplicada. Revista do Departamento de Geografia, 16 (2005) 81-90. Disponível em: http://www.doaj.org/doaj?func=abstract $\&$ id=1074436. Acesso: Set/2012. 